\title{
Male Hormonal Contraception: Where Are We Now?
}

\author{
Christina Wang ${ }^{1,3} \cdot$ Mario P. R. Festin ${ }^{2}$ Ronald S. Swerdloff ${ }^{3}$
}

Published online: 29 January 2016

(C) Springer Science+Business Media New York 2016

\begin{abstract}
Hormonal male contraception clinical trials began in the 1970s. The method is based on the use of exogenous testosterone alone or in combination with a progestin to suppress the endogenous production of testosterone and spermatogenesis. Studies using testosterone alone showed that the method was very effective with few adverse effects. Addition of a progestin increases the rate and extent of suppression of spermatogenesis. Common adverse effects include acne, injection site pain, mood change including depression, and changes in libido that are usually mild and rarely lead to discontinuation. Current development includes long-acting injectables and transdermal gels and novel androgens that may have both androgenic and progestational activities. Surveys showed that over $50 \%$ of men will accept a new male method and female partners will trust their partner to take oral "male pills." Partnership between government,
\end{abstract}

This article is part of the Topical Collection on Family Planning

Christina Wang

wang@labiomed.org

Mario P. R. Festin

festinma@who.int

Ronald S. Swerdloff

swerdloff@labiomed.org

1 Clinical and Translational Science Institute, Los Angeles Biomedical Research Institute, Harbor-UCLA Medical Center, 1000 W. Carson Street, Torrance, CA 90509, USA

2 UNDP/UNFPA/UNICEF/WHO/World Bank Special Programme of Research, Development, and Research Training in Human Reproduction, World Health Organization, 20 Avenue Appia, CH 1211 Geneva, Switzerland

3 Division of Endocrinology, Department of Medicine, Harbor-UCLA Medical Center, 1000 W. Carson Street, Torrance, CA 90509, USA nongovernment agencies, academia, and industry may generate adequate interest and collaboration to develop and market the first male hormonal contraception.

Keywords Male contraception · Androgens · Progestins · Spermatogenesis suppression $\cdot$ Contraceptive efficacy

\section{Introduction}

Despite improvement in modern female contraceptive methods and the ability to rapidly introduce new effective methods to developing countries, there are unmet needs for family planning in women 15 to 49 years [1-3]. Achieving the desired number of children is beneficial to women, families, and society. In order to meet the unmet need for women, countries need to make available modern contraceptives, provide high quality services, and improve access to such services. In addition, development of new methods of contraception involving men should be a priority. Male contraceptive methods available to the public include the condom which has a high user failure rate [4] and vasectomy which is considered irreversible and involves a minor surgical procedure.

The mechanisms of action of hormonal male contraception is based on the suppression of the secretion and production of the gonadotropins, both luteinizing and follicle stimulating hormone (LH, FSH), from the pituitary by exogenous sex steroids (androgens with or without progestins) or gonadotropin releasing hormone ( $\mathrm{GnRH}$ ) analogues. Gonadotropin suppression results in marked decrease in intratesticular testosterone and suppression of spermatogenesis. This profound suppression of sperm output inhibits fertility in men providing an effective male-directed contraceptive method. Sexual function, male characteristics, and effects on nonreproductive organs are maintained by the androgen (usually testosterone) 
that is part of the contraceptive regimen. The current goal is to identify a hormonal male contraceptive that is effective, reversible, safe, acceptable, affordable, and available. The focus has been on the development of a long-acting hormonal delivery system such as testosterone undecanoate intramuscular injections (IM) or user-friendly provider-independent combinations of androgens and progestins such as transdermal applications of combined testosterone and nestorone gels or novel androgens that have activity of both hormones [5-8].

\section{Early Studies Demonstrating Efficacy of Hormonal Male Contraception (Table 1)}

Beginning in the early 1970s, the National Institutes of Health (NIH) in the USA began male hormonal contraceptive clinical trials using testosterone enanthate, an intramuscular (IM) injectable preparation available in many countries since the 1950 s with good safety profile. These early studies showed when small numbers of healthy male volunteers were administered testosterone enanthate IM for several months, sperm concentration was markedly suppressed to very low levels (oligozoospermia, low sperm concentration arbitrarily defined as $<5$ or $<3$ million/ml in studies in the 1990 s and $<1$ million/ $\mathrm{ml}$ in more recent studies, and azoospermia, no sperm cells in ejaculate) in a high proportion of men [9-12]. The World Health Organization (WHO) undertook two multicenter, multinational studies involving larger numbers of healthy men in the 1990s that established the efficacy of male hormonal contraception when sperm output was suppressed to very low levels. The first study recruited 271 healthy couples from ten centers in seven countries in four continents [13]. Testosterone enanthate was administered IM every week for $\leq 6$ months until the men achieved azoospermia (Table 1). After azoospermia was reached, 157 couples used the weekly testosterone enanthate injections as their only method of contraception, and 119 couples completed the efficacy of 12 months. There was one pregnancy in 1486 months of efficacy evaluation (Pearl Index 0.8 [95 \% confidence interval (CI) 0.02-4.5] per 100 person-years; Pearl Index is the most common measure of the effectiveness of contraceptive methods and is based on the number of pregnancies, the number of women, and time exposed to the method) [13]. The second study followed using the same study design except the couples were eligible for entry into the efficacy phase when the male partner developed severe oligozoospermia (initially arbitrarily defined as $<5$ million $/ \mathrm{ml}$ ejaculate, later revised as $<3$ million $/ \mathrm{ml}$ ). The study recruited 399 couples from three countries in Asia, and six countries in Australia, Europe, and North America. Three hundred and fifty-seven men (89\%) completed the efficacy phase with eight men $(2.2 \%)$ failing to reach the threshold for oligozoospermia (Table 1). After 180 person-years of exposure, five pregnancies occurred with three occurring when sperm concentration was $>4$ million $/ \mathrm{ml}$, and the threshold criteria for entry into efficacy phase was lowered to $<3$ million $/ \mathrm{ml}$. No pregnancy occurred in the azoospermic group, and four occurred in the oligozoospermic group. The overall pregnancy rate was 1.4 (95\% CI 0.4 to 3.7 ) per 100 personyears. In these two studies, the azoospermia rate was higher in Asian men, with non-Asian less likely to achieve suppression to severe oligozoospermia. The study also demonstrated that the pregnancy rate in the couples in the efficacy phase was related to the sperm output of the male partner. These two early landmark studies provided strong evidence that when spermatogenesis is suppressed to yield very low sperm output by the administration of exogenous androgens, contraceptive efficacy can be as high as female contraceptive methods [14].

These two large-scale studies were confirmed by a smaller contraceptive efficacy study using testosterone implants. In the first single center study, the investigators implanted 800 or 1200-mg testosterone implants into the abdominal wall with or without a 5-alpha-reductase inhibitor to suppress intratesticular dihydrotestosterone levels. The rationale of adding a 5-alpha-reductase inhibitor was to completely suppress the conversion of testosterone to the active androgen dihydrotestosterone in the testis and more effective suppression of spermatogenesis. When the sperm concentration reached $<1 \mathrm{million} / \mathrm{ml}$ in the male partner, the 16 couples were allowed to enter the efficacy phase with 16 . No pregnancy occurred during 214 months of exposure [15].

\section{Development of Androgens, Progestins, and GnRH Antagonists as Potential Male Contraceptives}

Studies that followed examined adding progestins and GnRH analogues to the androgen (testosterone) to increase the rate of suppression of spermatogenesis to severe oligozoospermia to over $90 \%$ in men. Progestins including depot medroxyprogesterone acetate, levonorgestrel pills and implants, desogestrel pills, etonogestrel implants, oral cyproterone acetate pills, and norethindrone enanthate injectables have been used in combination with testosterone implants, injectables, and transdermal preparations. These small contraceptive clinical trials showed that addition of a progestin increased the proportion of men whose spermatogenesis was suppressed to produce very low sperm output $(<1$ million/ ml) [16-18]. A two-center study employed a combination of testosterone implants $800 \mathrm{mg}$ every 4 months together with depot medroxyprogesterone acetate $300 \mathrm{mg}$ IM every 3 months. Efficacy phase of the study began when the male partner had two consecutive monthly semen samples with sperm concentration $<1$ million/ml. Fifty-five couples enrolled in the study, and 51 couples entered the efficacy phase. There was no pregnancy reported during the 425 months of 


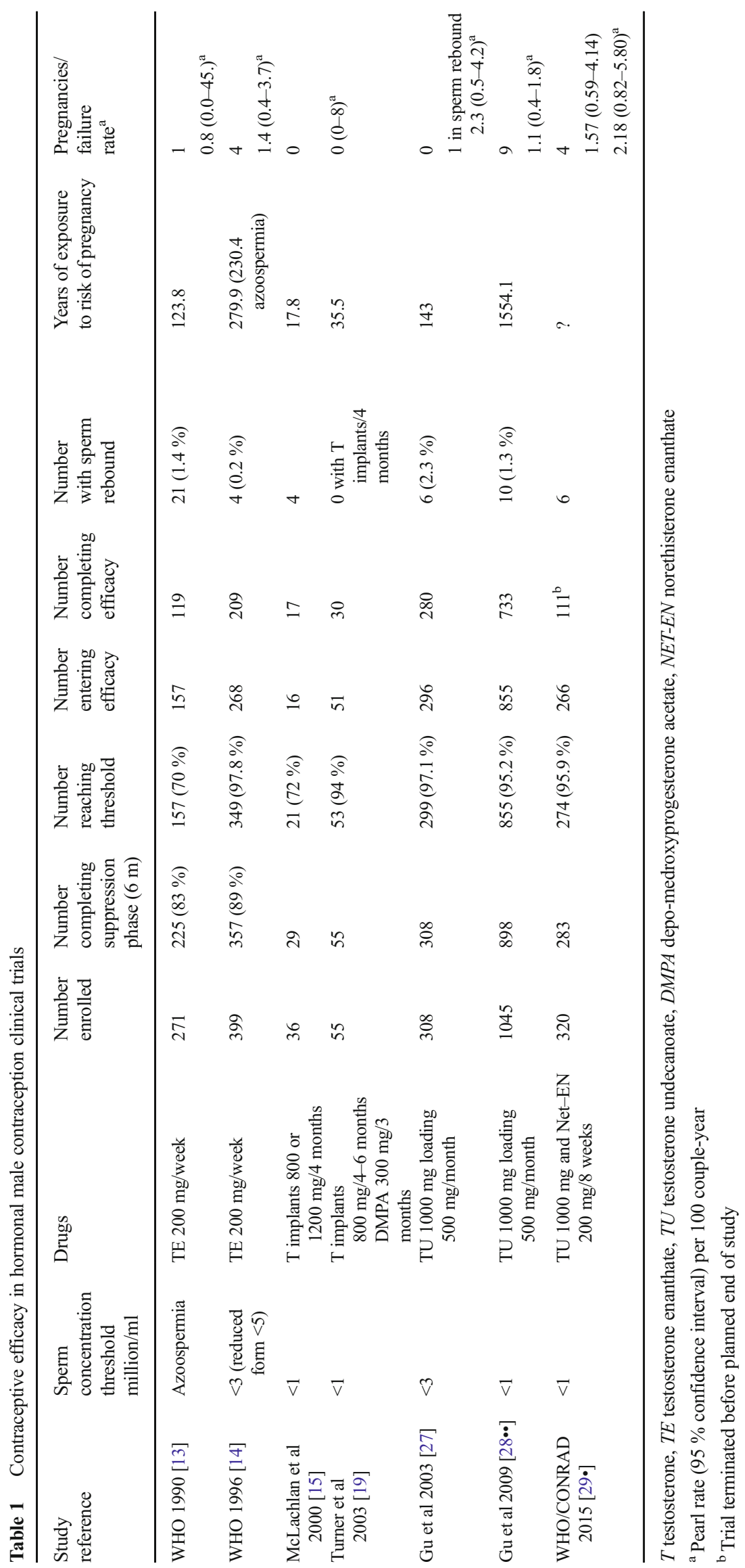


exposure. The contraceptive failure rate was zero ( $95 \%$ CI 0 to 8 ) per 100 person-years (Table 1) [19].

GnRH agonists downregulate gonadotropin receptor actions that result in initial elevation but subsequent marked suppression of the gonadotropins. GnRH antagonists act by competitive binding to receptors and reduced both $\mathrm{LH}$ and FSH to very low levels. GnRH agonists were not effective suppressors of sperm output [20,21], whereas the antagonists were very effective. Unfortunately, clinical studies showed that GnRH antagonists required frequent subcutaneous injections and were expensive to produce. Some of the antagonists caused a histamine-like acute reaction on the skin [22, 23]. Subsequent short-term studies showed that the suppression of spermatogenesis by $\mathrm{GnRH}$ antagonists plus an androgen can be maintained by administration of the androgen alone [24, 25]. Because GnRH antagonists required frequent injections, orally bioavailable GnRH antagonists are being developed but not yet available for testing as a contraceptive agent.

\section{More Recent Contraceptive Efficacy Trials with Injectable Testosterone Undecanoate and Norethisterone Enanthate (Table 1)}

New testosterone delivery systems have been developed for testosterone replacement in hypogonadal men. Testosterone undecanoate administered as IM injection was studied as a potential long-acting hormonal male contraceptive agent [26]. Chinese investigators studied spermatogenic suppression by testosterone undecanoate administered as a monthly injection to 308 volunteers. During a 6-month suppression phase, 9 out of 308 men did not reach a sperm concentration of $<3$ million/ml (failure of suppression $2.9 \%$ ) and 296 men entered the efficacy phase of 6 months. There were no pregnancies when the men had azoospermia or severe oligozoospermia. Sperm rebound to levels above threshold during treatment occurred in $2.3 \%$, and one pregnancy occurred during sperm rebound [27]. Based on these encouraging results, these investigators conducted a phase 3 mutlicenter contraceptive efficacy study in 1045 men in ten centers in China. Testosterone undecanoate $500 \mathrm{mg}$ was administered as a monthly injection after an initial loading dose of testosterone undecanoate $1000 \mathrm{mg}$. During the suppression phase of 6 months, $43 / 898$ participants $(4.8 \%)$ did not reach sperm concentration of $<1 \mathrm{million} / \mathrm{ml}$. Eight hundred fifty-five couples entered efficacy phase of 24 months, and 733 completed the study. During treatment period, $1.3 \%$ of subjects had a sperm rebound during treatment. During the efficacy phase, nine pregnancies occurred of which six might have been due to sperm rebound. There were 1554 months of exposure, and the failure rates were $1.0 \%$ (95\% CI 0.3 to $1.7 \%$ ) and 1.1 (95\% CI 0.4 to 1.8 ) at the end of 12 and 24 months, respectively. The study provided substantial evidence that testosterone undecanoate alone may provide a safe, effective, reversible contraceptive formulation for Asian men [28••].

Because of the finding in non-Asian men that the suppression of spermatogenesis may not be as efficacious using androgen alone, the World Health Organization (WHO) together with the Contraceptive Research and Development Program (CONRAD) at Eastern Virginia Medical School led a multicenter, multinational study that recruited 320 men who were given a combination of testosterone undecanoate $(1000 \mathrm{mg})$ and a progestin norethisterone enanthate $(200 \mathrm{mg})$ every 8 weeks with a suppression phase of up to 6 months and an efficacy phase (no other method of contraception for the couple) for 12 months. These 320 participants received at least one injection, and $95.9 \%$ reached the efficacy eligibility of sperm concentration $<1$ million $/ \mathrm{ml}$. Four pregnancies occurred in 266 couples participating in the study during the efficacy phase giving a contraceptive failure rate of 1.5 (95\% CI 0.59 to 4.14 ) per 100 users. Common adverse events included acne, pain at injection site, and mood changes which led to the WHO Human Reproduction Program Research Project Review Panel to recommend halting further injections before the planned end of study. Despite the early termination, this study provided additional evidence that an androgen plus a progestin achieved suppression of spermatogenesis to very low levels in over $95 \%$ of men and a failure rate of $1.5 \%$ consistent with the results of the early studies [29•]

\section{Reported Adverse Events from Male Hormonal Contraception Clinical Trials (Table 2)}

Testosterone and its esters are used as replacement therapy for hypogonadal men, and their side effects are well-known [30-32]. The common side effects are acne, oiliness of skin, weight gain, decrease in high-density lipoprotein (HDL) cholesterol, increases in hematocrit and hemoglobin, and sleeprelated breathing disorders. These adverse effects may be dependent on the dose and methods of testosterone administration. The potential long-term effects on the prostate are not known. It is unlikely that testosterone replacement causes benign prostatic hyperplasia or prostate cancer [32]. Because of the standard of care requiring monitoring of testosterone treatment with digital rectal examination and serum prostatespecific antigen concentrations in many clinical trials, this may result in more prostate biopsies [32]. Recent controversy on testosterone therapy and cardiovascular disease stemmed from controversial epidemiological studies [33-35] and metaanalyses $[36,37]$ where some of the studies showed that testosterone therapy may be associated with increases in cardiovascular disease risk including myocardial infarction and stroke and others demonstrated opposite results. The United States Food and Drug Administration and many experts in the 
Table 2 Adverse events reported in larger scale male contraceptive clinical trials (over 50 men per group)

\begin{tabular}{|c|c|c|c|c|c|c|c|c|}
\hline \multirow[t]{2}{*}{ Clinical trial } & \multirow[b]{2}{*}{$N$} & \multirow[b]{2}{*}{$\begin{array}{l}\text { Pain/problems } \\
\text { with injection/implant }\end{array}$} & \multicolumn{6}{|c|}{ Adverse events ( $\%$ of enrolled subjects) } \\
\hline & & & Acne & Weight gain & $\begin{array}{l}\text { Mood } \\
\text { changes }^{\text {g }}\end{array}$ & $\begin{array}{l}\text { Libido } \\
\text { changes }\end{array}$ & $\begin{array}{l}\text { Behavior } \\
\text { change }^{i}\end{array}$ & Fatigue \\
\hline \multicolumn{9}{|l|}{ Testosterone only } \\
\hline TE [13] & 271 & 7.5 & 29.5 & 4.4 & 1.5 & 4.4 & 2.6 & 8.1 \\
\hline $\mathrm{TE}[14]^{\mathrm{a}}$ & 399 & 5.3 & 2.0 & 0.5 & 1.0 & 0.8 & 0.8 & 0 \\
\hline TU $2003[27]$ & 308 & + & 6.8 & + & 0 & + & 0 & 0 \\
\hline TU $2009[28 \cdot \bullet]^{\mathrm{b}}$ & 1045 & 3.9 & 7.4 & + & 0.8 & + & $?$ & 0 \\
\hline \multicolumn{9}{|l|}{ Testosterone + Progestin } \\
\hline T implants DMPA [19] $]^{\mathrm{a}, \mathrm{c}}$ & 55 & 10.9 & $?$ & + & 1.2 & $+{ }^{d}$ & $?$ & $+{ }^{d}$ \\
\hline \multirow[t]{2}{*}{ TU+ Etonogestrel implants $[42 \cdot]^{\mathrm{e}}$} & Active 297 & 0.6 & 26 & 24 & 19 & 13 & $?$ & + \\
\hline & Placebo 52 & 2 & 10 & 10 & 10 & 0 & $?$ & $?$ \\
\hline TU + NET-EN $[29 \bullet]^{\mathrm{f}}$ & 320 & 23.1 & 45.9 & 3.8 & 24.4 & 42.2 & 5.7 & 1.6 \\
\hline \\
\hline \multicolumn{9}{|c|}{${ }^{\mathrm{b}}$ Cough after injections in $2.1 \%$; facial swelling/rash $0.8 \%$} \\
\hline \multicolumn{9}{|c|}{$\begin{array}{l}{ }^{\mathrm{c}} \text { Two serious adverse events: myotonic dystrophy during recovery phase and multiple congenital malformations (Vater Anomalad) in one twin } \\
\text { conceived during recovery phase. Both considered not related }\end{array}$} \\
\hline \multicolumn{9}{|c|}{$\begin{array}{l}\text { d Symptoms of hypogonadism (lethargy and sexual dysfunction) occurred in men during month } 5 \text { or } 6 \text { after T implants because of inadequate testosterone } \\
\text { release from the pellets after } 4 \text { months. This necessitated a protocol amendment }\end{array}$} \\
\hline \multicolumn{9}{|c|}{${ }^{\mathrm{e}}$ Night sweating was reported in $27 \%$ of men in the active group versus $8 \%$ in the placebo group } \\
\hline \multicolumn{9}{|c|}{$\begin{array}{l}{ }^{\mathrm{f}} \text { Most of the adverse events are mild or moderate, and many occurred in one center: acne ( } 90 \% \text { mild), mood changes (includes } 16.9 \% \text { emotional } \\
\text { changes, } 97 \% \text { mild; } 4.7 \% \text { mood swings; } 84 \% \text { mild; and } 2.8 \% \text { depression, five subjects had moderate and two subjects had severe depressive mood/ } \\
\text { depression), injection site pain ( } 93 \% \text { mild), libido changes (mainly increase; } 88 \% \text { mild), and behavior changes ( } 83 \% \text { mild) }\end{array}$} \\
\hline \multicolumn{9}{|c|}{${ }^{\mathrm{g}}$ Mood changes include emotional disorder, mood swings, altered mood, and depression } \\
\hline \multicolumn{9}{|c|}{${ }^{\mathrm{h}}$ Libido changes include increase or decrease libido } \\
\hline & & & & & & & & \\
\hline
\end{tabular}

field have expressed their opinion that the evidence for or against cardiovascular risk is inadequate and long-term adequately powered safety studies would be required.

In the larger scale contraceptive clinical trials using testosterone enanthate $200 \mathrm{mg}$ every week, which is a supraphysiological dose, the reported common adverse events include pain at injection site, acne, weight gain, fatigue, and mood changes including aggressiveness leading to discontinuation in $5.5,3.3,0.7,0.3$, and $1.4 \%$ of men, respectively. Increased or decreased libido and disturbed sleep occurred in a small number of subjects [38]. In the more recent contraceptive clinical trials using testosterone undecanoate $(1000 \mathrm{mg}$ loading and then $500 \mathrm{mg}$ every week) in over $1000 \mathrm{men}$, the most common reported side effects were pain at site of injection $(3.9 \%)$, acne $(7.4 \%)$, coughing after injection $(2.1 \%)$, and mood or behavior changes $(0.8 \%)$ [28••] (Table 2).

There are few clinical trials utilizing combined testosterone plus a progestin with large number of subjects. When testosterone implants were administered with depot medroxyprogesterone acetate, discontinuations were due to mainly to problems of implants (extrusion, pain, androgen deficiency due to inadequate testosterone delivery by implants, mood fluctuation, or study-unrelated personal reasons) [19]. In the most recent contraceptive efficacy study where testosterone undecanoate $1000 \mathrm{mg}$ was combined with norethisterone enanthate $200 \mathrm{mg}$ every 8 weeks, there were adverse events in the 320 participants including the following: acne, injection site pain, increased or decreased libido, mood changes including mood swings and depression, aggression and hostility, and muscle and skeletal pain. One center reported many of the adverse events. This study was stopped prematurely because of these adverse events [29•]. In these studies, changes in sexual function or mood were not prospectively monitored at the sites, and there was no placebo group. In studies where sexual function and mood were monitored prospectively by a diary [39], no significant negative changes in sexual function were found [40, 41•].

In the placebo-controlled randomized clinical trial using injectable testosterone decanoate and etonogestrel implants which were highly effective in suppressing spermatogenesis, adverse events that were reported to occur more frequently in the active treatment groups include acne, increase in body 
weight, libido change, mood changes, and night sweating [42•] (Table 2). There is no uniform requirement of reporting or coding of adverse events in these contraceptive studies, as the earlier studies reported adverse events leading to discontinuation, whereas the more current reports contained all adverse events.

Laboratory tests to evaluate safety outcomes showed no significant changes in renal or liver function. As anticipated with testosterone treatment, significant increases in hematocrit and hemoglobin are observed in most studies, but discontinuation due to increases in red cell indices is infrequent. Highdensity lipoprotein cholesterol levels are also decreased by testosterone or testosterone plus progestin, but the clinical significance of small decreases in high-density lipoprotein cholesterol is not known because of the complexities of lipoprotein metabolism and the relationship with risk of cardiovascular disease $[43,44]$.

\section{Factors Affecting Suppression of Spermatogenesis and Reversibility of Hormonal Male Contraception}

In an integrated analysis where semen analyses and clinical data were available from 1549 healthy male volunteers who participated in many hormonal male contraception clinical trials, using androgens or androgens plus progestins showed that addition of a progestin increased the rate and extent of suppression. In response to male hormonal contraceptive agents, non-Asian men suppressed spermatogenesis faster initially, but eventually, they achieved a less complete suppression of sperm output [45*]. This study confirmed the earlier reports that Asian men had more complete suppression of sperm production than non-Asian men $[13,14]$. The reason for this difference is not known, but several mechanisms have been proposed. There are differences in testicular histomorphology and testosterone metabolism between EastAsian and Caucasian men. However, whether this contributes significantly to varying degrees of sperm suppression in response to exogenous hormonal male contraception is not clear [46]. Because of these differences between Asian and nonAsian men, the path of male hormonal contraceptive development has focused on androgens plus progestins.

Male hormonal agents are frequently used in female contraception, known to suppress gonadotropins, and reversibility has been assumed. The same integrated analysis examined whether all men recovered from male hormonal contraceptive agents that suppressed sperm output to very low regions. The study showed that the median time to recovery to 10 million/ $\mathrm{ml}$ was 3 months and to $20 \mathrm{million} / \mathrm{ml}$ was 3.4 months which is the anticipated time to recovery. These sperm concentrations are compatible with male fertility. The probability of recovery to 20 million with 12 months is 90 and $100 \%$ within 24 months. The recovery rates were slower with longer duration of treatment, use of longer acting hormonal preparations, and non-Asian ethnicity. The recovery rates were higher with older age, men who suppressed spermatogenesis faster, higher baseline sperm concentration, and lower baseline serum luteinizing hormone, but these effect sizes were very small $[47 \bullet \bullet, 48]$. The conclusion from this study was that all men would recover after hormonal male contraception indicating that efforts to develop this reversible and efficacious method of contraception should continue.

\section{Newer Agents Used for Hormonal Male Contraception}

The focus of hormonal male contraception development in recent years has been the development of novel androgens that may be more potent than testosterone in the suppression of gonadotropins and with fewer potential side effects. 7Alpha-methyl-19-nortestosterone (MENT) cannot be 5-alpha reduced to dihydrotestosterone like steroids and may have less stimulating effects on the prostate gland. In rats, MENT is ten times more potent than testosterone in the muscle and only four times more potent in the prostate gland suggesting less simulating effects on the prostate compared to testosterone [49]. This was confirmed in monkeys [50]. Initial studies using MENT as an implant in men showed very effective suppression of spermatogenesis with four MENT implants (releasing a total of $1600 \mathrm{mcg} /$ day MENT) [51]. MENT implants are under development to optimize the delivery rate as a 1-year implant by the Population Council [52].

Another androgen, dimethandrolone (DMA, 7-alpha,11beta-dimethyl-19-nortestosterone) undecanoate, is being developed as an oral preparation as well as an intramuscular injection. In the body, DMA undecanoate (DMAU) is converted to DMA which is the active entity. In in vitro studies, DMA showed dose-dependent androgenic and progestational activities. The dual activities on the androgen and progesterone receptors may create a single agent capable of suppressing spermatogenesis while maintaining androgenic activity in men [53]. DMAU has antifertility effects in male rabbits [54]. A single-dose escalation study in healthy male volunteers showed that DMAU appeared to be safe and well-tolerated. DMAU has to be administered with a fatty meal to enhance absorption from the gastrointestinal tract. After administration of a single dose of DMAU powder (at a dose $>200 \mathrm{mg}$ /day), significant suppression of serum gonadotropins and testosterone occurred which had not been reported with other hormonal agents [55]. Repeat daily dosing of DMAU over 28 days is currently in progress where the goals are to study safety and tolerability as well as the extent of suppression of gonadotropins. It is also being formulated as an injection by the National Institute of Child Health and Human Development (NICHD), National Institutes of 
Health, USA, for hormonal male contraception studies. NICHD is also developing levonorgestrel butanoate as a long-acting progestin injection for male and female contraception.

Nestorone (16-methylene-17alpha-acetoxy-19-norpregn4-ene-3,20-dione) is a potent progestin that has minimal androgen or estrogen activity. The Population Council is developing nestorone for both female and male contraception [52, $56,57]$. Nestorone applied transdermally has been used in combination with testosterone gel for hormonal contraception clinical trials in men. Nestorone and testosterone gels when applied on the skin suppressed both gonadotropins (LH and FSH) to very low levels in healthy male volunteers [58]. In a 6-month study, a combined gel (testosterone $100 \mathrm{mg}$ /day and nestorone $8 \mathrm{mg} /$ day on skin) suppressed sperm output to $<1$ million/ml in $89 \%$ of men compared to $23 \%$ of those who applied testosterone gel alone. There were minimal adverse effects $[41 \cdot 59]$. Based on the studies, a contraceptive efficacy study is planned for 2016 using a combined nestorone and testosterone gel as a provider independent daily application on the skin.

\section{Men Will Use Male Contraception and Their Partners Approve Development of Male Contraception}

Acceptability of male contraception was studied with interviews in seven cities in Asia, North and South America, and Europe that were conducting male hormonal contraceptive studies supported by the World Health Organization. The study planned to gauge the male users' evaluation of the hormonal method compared to other male methods and whether these hormonal methods modify sexual function and behavior [60]. The study showed that a daily pill or a monthly injectable might have the highest acceptability; monthly interviews appeared to be useful in assessing any sexual dysfunction associated with the new method. Other studies of men participating in clinical trials using various nonvalidated questionnaires showed that in some studies over $61 \%$ of participants found testosterone undecanoate injectable method excellent or good [61], while other studies showed that transdermal application is acceptable in about $56 \%$ of men $[62,63]$. In the monthly injections of testosterone undecanoate clinical trial in China [27], most participants (male and female), providers, and policy makers thought that a new hormonal method would be acceptable if proven to be safe and effective. In the 308 men who were receiving the injections, $72.3 \%$ thought monthly injections and semen analyses, and the need to use another contraceptive method during the period of sperm suppression were inconveniences that might reduce the acceptability of the method [64]. Future studies of acceptability of male contraceptive method will require the development of validated questionnaires. If the surveys are conducted in participants in male contraceptive trials, the data collected may be biased and are not reflective of the general population.

Structured interviews using questionnaires in four cities (Edinburgh, Cape Town, Shanghai, and Hong Kong) in three countries, UK, South Africa, and China, showed that 44 to $83 \%$ of men would use a male contraceptive pill. A pill was preferred to an injectable. Acceptability was variable and influenced by knowledge of other contraceptive methods and cultural background [65]. In another study that surveyed over 9000 men (18 to 50 years) in nine countries and four continents showed that in 55 to $81.5 \%$ of couples, both partners were involved in selecting the method of contraception. From 28.5 to $71.4 \%$ of men surveyed expressed willingness to use a new male method of contraception with wide variation among different racial and ethnic groups [66 ${ }^{\circ}$. In a study in England $(n=380)$, both men and women had favorable attitudes to a male contraceptive pill. Women had a more positive attitude to the new male pill but had less trust that men would use it effectively. Men in a stable relationship had a more positive attitude toward a male pill than those in casual relationships [67]. The attitude of female partners was also studied in 1894 women attending family planning clinics in Edinburgh, Cape Town, Shanghai, and Hong Kong. Over $90 \%$ of women in Edinburgh and Cape Town considered a male pill a good idea, whereas in Hong Kong and Shanghai, the percent were lower at 71 and $87 \%$, respectively. Only $2 \%$ of women would not trust their partner to use a male pill [68].

These studies in men and women provided evidence that if a new male contraceptive method is available, over $50 \%$ of men may try to use it. Couples in stable relationships trust each other, and the female partner would trust the male taking a male contraceptive pill.

\section{Challenges to Bring Male Hormonal Methods to Become Available to Men}

Male contraception can fill an unmet need in contraception, and based on published surveys, this would be acceptable to many men and their partners. In addition, new male methods may relieve the contraceptive burden of women. Because the required visits to the clinic and interviews with physicians or providers knowledgeable in reproduction may make men more aware of their reproductive health. Since the 1970s, hormonal male contraceptive trials have been conducted in many parts of the world. Large-scale studies from 1990s and those from more recent times showed that hormonal contraception with androgens alone is very efficacious in Asian men and regimens with androgens and progestins are efficacious in all men. The possibility of escape from suppression of sperm production in men by an androgen alone regimen may be higher than in androgen and progestin combinations. The 
use of two agents for male contraception is more complex as the bioavailability and pharmacokinetics of the two entities should be complementary to each other. Mismatching injectable testosterone long-acting injections with a slower increase in serum testosterone level with shorter acting injectable progestins that have a rapid burst effect may result in inadequate androgen effects and symptoms of hypogonadism in the presence of high progestin levels. The current goals of clinical investigation are to find different combinations of androgens and progestins that have similar pharmacokinetics with additive action on suppression of spermatogenesis and minimal adverse effects. Newer hormonal steroids that have both androgenic and progestational activity are being developed in addition to DMAU. The selected agents must be safe without major adverse effects and can be delivered in a user friendly method, e.g., daily pill or transdermal gels or three monthly or yearly injections, and if possible without surgical intervention. The steady delivery of hormonal steroids for male contraception has been perceived to have less adverse events than those that provide serum peaks and troughs of the androgen or the progestin. The goal is to develop a number of male hormonal contraceptives such as long-acting injectables, implants, pills, and transdermal gels to meet the preferences of men and their partners.

The economic aspects of male hormonal contraception have been studied. Assuming a market size of 10 million men in the USA and 50 million men worldwide, the market value of a new male contraceptive method is estimated to be worth 40 to 200 billion dollars [69]. The NICHD currently supports the development of novel targets for male contraception as well as funding to male hormonal contraceptive clinical trials. The Population Council's contraceptive development focuses on Nestorone and MENT.

The pharmaceutical industry has withdrawn support in research and development of contraception. This lack of industry support despite a large potential market is disappointing but may be due to several concerns including that men will not use the prescribed contraception method consistently, cost of male hormonal methods and differential pricing for developed and developing countries, and potential unknown long term side effects. Thus, government and academia will need to collaborate with community advocates to generate interest in smaller, specialty pharmaceutical companies that are interested in reproductive health. Advocacy from public interest groups will also help to push the agenda forward for male contraceptive development.

\section{Conclusion}

Large-scale clinical trials in men proved that when sperm output is suppressed to a very low level, the contraceptive efficacy is very high. Androgens plus a progestin will most likely be the first hormonal contraception method for men. The matching of a progestin to testosterone may be more complex, and a balance between the two steroids may be necessary to produce a viable, safe, and reversible male hormonal contraception. Surveys in men and women in the reproductive age group suggest that many men and women would accept male hormonal methods as a contraceptive option. Partnership between government, nongovernment agencies, academia, and industry will identify the best combinations of steroids to bring forward, conduct clinical trials, and submit reports to regulatory agencies for approval, and ensure accessibility of these approved agents by all men.

Acknowledgments Drs. Wang and Swerdloff are supported by research contracts from the NICHD NO1 Contract HHSN275220130024I and research support from Clarus Therapeutics, Lipocine, Besins Healthcare International. Dr. Wang is supported by the National Center for Advancing Translational Sciences through UCLA CTSI Grant UL1TR000124 and a grant from UNDP/UNFPA/UNICEF/WHO/World Bank Special Programme of Research, Development, and Research Training in Human Reproduction.

\section{Compliance with Ethical Standards}

Conflict of Interest Christina Wang declares grants from UNDP/ UNFPA/UNICEF/WHO/World Bank Special Programme of Research, Development, and Research Training in Human Reproduction, and grants from NIH, NICHD; she also declares grants from Clarus Therapeutics, Antares, and Besins Healthcare International; she declares a grant and personal fees from Lipocine (temporary advisor) and personal fees from TesoRX (temporary advisor).

Mario P. R. Festin declares no conflict of interest.

Ronald S. Swerdloff declares grants from NIH, NICHD, and grants from Clarus Therapeutics, Besins Healthcare International, and Antares; he declares a grant and personal fees from Lipocine and personal fees from TesoRX.

Human and Animal Rights and Informed Consent This article does not contain any studies with human or animal subjects performed by any of the authors.

\section{References}

Papers of particular interest, published recently, have been highlighted as:

- Of importance

•. Of major importance

1. Darroch JE, Singh S. Trends in contraceptive need and use in developing countries in 2003, 2008, and 2012: an analysis of national surveys. Lancet. 2013;381(9879):1756-62.

2. Peterson HB, Darmstadt GL, Bongaarts J. Meeting the unmet need for family planning: now is the time. Lancet. 2013;381(9879): 1696-9.

3. Alkema L, Kantorova V, Menozzi C, et al. National, regional, and global rates and trends in contraceptive prevalence and unmet need 
for family planning between 1990 and 2015: a systematic and comprehensive analysis. Lancet. 2013;381(9878):1642-52.

4. Trussell J. Contraceptive failure in the United States. Contraception. 2011;83(5):397-404.

5. Nieschlag E. Hormonal male contraception: end of a dream or start of a new era? Endocrine. 2013;43(3):535-8.

6. Roth MY, Page ST, Bremner WJ. Male hormonal contraception: looking back and moving forward. Andrology. 2015;4(1):4-12.

7. Wang C, Swerdloff RS. Hormonal approaches to male contraception. Curr Opin Urol. 2010;20(6):520-4.

8. Page ST, Amory JK, Bremner WJ. Advances in male contraception. Endocr Rev. 2008;29(4):465-93.

9. Swerdloff RS, Campfield LA, Palacios A, et al. Suppression of human spermatogenesis by depot androgen: potential for male contraception. J Steroid Biochem. 1979;11(1B):663-70.

10. Cunningham GR, Silverman VE, Thornby J, et al. The potential for an androgen male contraceptive. J Clin Endocrinol Metab. 1979;49(4):520-6.

11. Steinberger E, Smith KD. Testosterone enanthate a possible reversible male contraceptive. Contraception. 1977;16(3):261-8.

12. Steinberger E, Smith KD. Effect of chronic administration of testosterone enanthate on sperm production and plasma testosterone, follicle-stimulating hormone, and luteinizing hormone levels: a preliminary evaluation of a possible male contraceptive. Fertil Steril. 1977;28(12):1320-8.

13. World Health Organization Task Force on Methods for the Regulation of Male Fertility. Contraceptive efficacy of testosterone-induced azoospermia in normal men. World Health Organization Task Force on methods for the regulation of male fertility. Lancet. 1990;336(8721):955-9.

14. World Health Organization Task Force on the Regulation of Male Fertility. Contraceptive efficacy of testosterone-induced azoospermia and oligozoospermia in normal men. Fertil Steril. 1996;65(4): $821-9$.

15. McLachlan RI, McDonald J, Rushford D, et al. Efficacy and acceptability of testosterone implants, alone or in combination with a 5alpha-reductase inhibitor, for male hormonal contraception. Contraception. 2000;62(2):73-8.

16. Nieschlag E, Zitzmann M, Kamischke A. Use of progestins in male contraception. Steroids. 2003;68(10-13):965-72.

17. Meriggiola MC, Farley TM, Mbizvo MT. A review of androgenprogestin regimens for male contraception. J Androl. 2003;24(4): 466-83.

18. Wang C, Swerdloff RS. Male hormonal contraception. Am J Obstet Gynecol. 2004;190(4 Suppl):S60-8.

19. Turner L, Conway AJ, Jimenez M, et al. Contraceptive efficacy of a depot progestin and androgen combination in men. J Clin Endocrinol Metab. 2003;88(10):4659-67.

20. Bhasin S, Heber D, Steiner BS, et al. Hormonal effects of gonadotropin-releasing hormone $(\mathrm{GnRH})$ agonist in the human male. III. Effects of long term combined treatment with $\mathrm{GnRH}$ agonist and androgen. J Clin Endocrinol Metab. 1985;60(5):9981003.

21. Behre HM, Nashan D, Hubert W, et al. Depot gonadotropinreleasing hormone agonist blunts the androgen-induced suppression of spermatogenesis in a clinical trial of male contraception. J Clin Endocrinol Metab. 1992;74(1):84-90.

22. Tom L, Bhasin S, Salameh W, et al. Induction of azoospermia in normal men with combined Nal-Glu gonadotropin-releasing hormone antagonist and testosterone enanthate. J Clin Endocrinol Metab. 1992;75(2):476-83.

23. Behre HM, Bockers A, Schlingheider A, et al. Sustained suppression of serum LH, FSH and testosterone and increase of highdensity lipoprotein cholesterol by daily injections of the GnRH antagonist cetrorelix over 8 days in normal men. Clin Endocrinol (Oxf). 1994;40(2):241-8.
24. Behre HM, Kliesch S, Lemcke B, et al. Suppression of spermatogenesis to azoospermia by combined administration of $\mathrm{GnRH}$ antagonist and 19-nortestosterone cannot be maintained by this nonaromatizable androgen alone. Hum Reprod. 2001;16(12):2570-7.

25. Swerdloff RS, Bagatell CJ, Wang C, et al. Suppression of spermatogenesis in man induced by Nal-Glu gonadotropin releasing hormone antagonist and testosterone enanthate (TE) is maintained by TE alone. J Clin Endocrinol Metab. 1998;83(10):3527-33.

26. Qoubaitary A, Meriggiola C, $\mathrm{Ng} \mathrm{CM}$, et al. Pharmacokinetics of testosterone undecanoate injected alone or in combination with norethisterone enanthate in healthy men. J Androl. 2006;27(6): 853-67.

27. Gu YQ, Wang XH, Xu D, et al. A multicenter contraceptive efficacy study of injectable testosterone undecanoate in healthy Chinese men. J Clin Endocrinol Metab. 2003;88(2):562-8.

28.• Gu Y, Liang X, Wu W, et al. Multicenter contraceptive efficacy trial of injectable testosterone undecanoate in Chinese men. J Clin Endocrinol Metab. 2009;94(6):1910-5. This phase three study recruited over 1000 men who were administered testosterone undecanoate injections of up to 30 month. The results showed spermatogenesis remained suppressed during the treatment phase with a low contracpetive falure rate.

29. Conrad CD, World Health Organization et al. Hormonal male contraception: a phase II clinical trial of Norethisterone Enanthate (NetEn) combined with Testosterone Undecanoate (Tu) in healthy men Andrology. 2013;(Suppl 1):30. This study used a combination of an adrogen testosterone undecanoate and a progestin norethindrone enanthate as a male contracpetive. The efficacy was very good but the study was preamturely terminated because of adverse events.

30. Bhasin S, Cunningham GR, Hayes FJ, et al. Testosterone therapy in men with androgen deficiency syndromes: an Endocrine Society clinical practice guideline. J Clin Endocrinol Metab. 2010;95(6): 2536-59.

31. Surampudi P, Swerdloff RS, Wang C. An update on male hypogonadism therapy. Expert Opin Pharmacother. 2014;15(9): 1247-64.

32. Fernandez-Balsells MM, Murad MH, Lane M, et al. Clinical review 1: adverse effects of testosterone therapy in adult men: a systematic review and meta-analysis. J Clin Endocrinol Metab. 2010;95(6): 2560-75.

33. Shores MM, Smith NL, Forsberg CW, et al. Testosterone treatment and mortality in men with low testosterone levels. J Clin Endocrinol Metab. 2012;97(6):2050-8.

34. Vigen R, O'Donnell CI, Baron AE, et al. Association of testosterone therapy with mortality, myocardial infarction, and stroke in men with low testosterone levels. JAMA. 2013;310(17):1829-36.

35. Finkle WD, Greenland S, Ridgeway GK, et al. Increased risk of non-fatal myocardial infarction following testosterone therapy prescription in men. PLoS One. 2014;9(1):e85805.

36. Corona G, Maseroli E, Rastrelli G, et al. Cardiovascular risk associated with testosterone-boosting medications: a systematic review and meta-analysis. Expert Opin Drug Saf. 2014;13(10):1327-51.

37. $\mathrm{Xu} \mathrm{L}$, Freeman G, Cowling BJ, et al. Testosterone therapy and cardiovascular events among men: a systematic review and metaanalysis of placebo-controlled randomized trials. BMC Med. 2013;11:108.

38. Wu FC, Farley TM, Peregoudov A, et al. Effects of testosterone enanthate in normal men: experience from a multicenter contraceptive efficacy study. World Health Organization Task Force on Methods for the Regulation of Male Fertility. Fertil Steril. 1996;65(3):626-36.

39. Lee KK, Berman N, Alexander GM, et al. A simple self-report diary for assessing psychosexual function in hypogonadal men. J Androl. 2003;24(5):688-98. 
40. Gonzalo IT, Swerdloff RS, Nelson AL, et al. Levonorgestrel implants (Norplant II) for male contraception clinical trials: combination with transdermal and injectable testosterone. J Clin Endocrinol Metab. 2002;87(8):3562-72.

41. Ilani N, Roth MY, Amory JK, et al. A new combination of testosterone and nestorone transdermal gels for male hormonal contraception. J Clin Endocrinol Metab. 2012;97(10):3476-86. This study showed that transdermal daily application of testosterone and nestorone gels aremore efficacious in the suppression of pserm output than testosterone alone.

42. Mommers E, Kersemaekers WM, Elliesen J, et al. Male hormonal contraception: a double-blind, placebo-controlled study. J Clin Endocrinol Metab. 2008;93(7):2572-80. This study included a placebo group that received both the injection and implants. The contraceptive efficacy of testosterone decanoate and etonogestrel implants was very high. The adverse events that were more common in the active versus the placebo arm were acne, weight gain, mood and libido changes.

43. Arora S, Patra SK, Saini R. HDL-A molecule with a multi-faceted role in coronary artery disease. Clin Chim Acta. 2015;452:66-81.

44. Barter PJ, Rye KA. Targeting high-density lipoproteins to reduce cardiovascular risk: what is the evidence? Clin Ther. 2015;37(12): 2716-31.

45. Liu PY, Swerdloff RS, Anawalt BD, et al. Determinants of the rate and extent of spermatogenic suppression during hormonal male contraception: an integrated analysis. J Clin Endocrinol Metab. 2008;93(5):1774-83. This study identified factors.

46. Ilani N, Liu PY, Swerdloff RS, et al. Does ethnicity matter in male hormonal contraceptive efficacy? Asian J Androl. 2011;13(4):579 84.

47.• Liu PY, Swerdloff RS, Christenson PD, et al. Rate, extent, and modifiers of spermatogenic recovery after hormonal male contraception: an integrated analysis. Lancet. 2006;367(9520):1412-20. This study provided evidence that hormonal male contraception is reversible.

48. Liu PY, Swerdloff RS, Wang C. Recent methodological advances in male hormonal contraception. Contraception. 2010;82(5):471-5.

49. Kumar N, Didolkar AK, Monder C, et al. The biological activity of 7 alpha-methyl-19-nortestosterone is not amplified in male reproductive tract as is that of testosterone. Endocrinology. 1992;130(6): 3677-83.

50. Cummings DE, Kumar N, Bardin CW, et al. Prostate-sparing effects in primates of the potent androgen 7alpha-methyl-19nortestosterone: a potential alternative to testosterone for androgen replacement and male contraception. J Clin Endocrinol Metab. 1998;83(12):4212-9.

51. von Eckardstein S, Noe G, Brache V, et al. A clinical trial of 7 alpha-methyl-19-nortestosterone implants for possible use as a long-acting contraceptive for men. J Clin Endocrinol Metab. 2003;88(11):5232-9.

52. Nieschlag E, Kumar N, Sitruk-Ware R. 7alpha-methyl-19nortestosterone (MENTR): the population council's contribution to research on male contraception and treatment of hypogonadism. Contraception. 2013;87(3):288-95.
53. Attardi BJ, Hild SA, Reel JR. Dimethandrolone undecanoate: a new potent orally active androgen with progestational activity. Endocrinology. 2006;147(6):3016-26.

54. Hild SA, Reel JR, Hoffman LH, et al. CDB-2914: anti-progestational/anti-glucocorticoid profile and post-coital anti-fertility activity in rats and rabbits. Hum Reprod. 2000;15(4):822-9.

55. Surampudi P, Page ST, Swerdloff RS, et al. Single, escalating dose pharmacokinetics, safety and food effects of a new oral androgen dimethandrolone undecanoate in man: a prototype oral male hormonal contraceptive. Andrology. 2014;2(4):579-87.

56. Kumar N, Koide SS, Tsong Y, et al. Nestorone: a progestin with a unique pharmacological profile. Steroids. 2000;65(10-11):629-36.

57. Sitruk-Ware R, Small M, Kumar N, et al. Nestorone: clinical applications for contraception and HRT. Steroids. 2003;68(10-13):90713.

58. Mahabadi V, Amory JK, Swerdloff RS, et al. Combined transdermal testosterone gel and the progestin nestorone suppresses serum gonadotropins in men. J Clin Endocrinol Metab. 2009;94(7):231320.

59. Roth MY, Ilani N, Wang C, et al. Characteristics associated with suppression of spermatogenesis in a male hormonal contraceptive trial using testosterone and Nestorone $((\mathrm{R}))$ gels. Andrology. 2013;1(6):899-905.

60. World Health Organization Task Force On Psychosocial Research on Family Planning. Acceptability of drugs for male fertility regulation: a prospectus and some preliminary data. Contraception. 1980;21(2):121-34.

61. Meriggiola MC, Cerpolini S, Bremner WJ, et al. Acceptability of an injectable male contraceptive regimen of norethisterone enanthate and testosterone undecanoate for men. Hum Reprod. 2006;21(8): 2033-40.

62. Amory JK, Page ST, Anawalt BD, et al. Acceptability of a combination testosterone gel and depomedroxyprogesterone acetate male contraceptive regimen. Contraception. 2007;75(3):218-23.

63. Roth MY, Shih G, Ilani N, et al. Acceptability of a transdermal gelbased male hormonal contraceptive in a randomized controlled trial. Contraception. 2014;90(4):407-12.

64. Zhang L, Shah IH, Liu Y, et al. The acceptability of an injectable, once-a-month male contraceptive in China. Contraception. 2006;73(5):548-53.

65. Martin CW, Anderson RA, Cheng L, et al. Potential impact of hormonal male contraception: cross-cultural implications for development of novel preparations. Hum Reprod. 2000;15(3):637-45.

66. Heinemann K, Saad F, Wiesemes M, et al. Attitudes toward male fertility control: results of a multinational survey on four continents. Hum Reprod. 2005;20(2):549-56. Large survey showed the acceptability of male contraception in over $50 \%$ of the men who participated.

67. Eberhardt J, van Wersch A, Meikle N. Attitudes towards the male contraceptive pill in men and women in casual and stable sexual relationships. J Fam Plan Reprod Health Care. 2009;35(3):161-5.

68. Glasier AF, Anakwe R, Everington D, et al. Would women trust their partners to use a male pill? Hum Reprod. 2000;15(3):646-9.

69. Dorman E, Bishai D. Demand for male contraception. Expert Rev Pharmacoecon Outcomes Res. 2012;12(5):605-13. 